Article

\title{
Sustainable Consumption in Everyday Life: A Qualitative Study of UK Consumer Experiences of Meat Reduction
}

\author{
Josephine Mylan \\ Sustainable Consumption Institute, University of Manchester, M13 9PL Manchester, UK; \\ josephine.mylan@manchester.ac.uk
}

Received: 24 April 2018; Accepted: 29 June 2018; Published: 4 July 2018

check for updates

\begin{abstract}
A reduction in meat consumption is increasingly considered fundamental to a sustainable food system. This paper contributes to understanding how meat consumers enact 'meat reduction' in the context of their everyday lives, exploring the motivations, strategies and experiences of eating less meat. Data were generated through twenty in-depth interviews with UK meat eaters, half of whom aimed to reduce their meat intake. Accounts from three meat-reducing respondents are used to present insights from the in-depth exploration of meat reduction in relation to broader practices of eating and food provision in daily life, interpreted through the lens of a practice-oriented understanding of consumption. Findings suggest that the enactment of meat reduction is determined by factors beyond individuals' ethical stance towards environmental issues or animal welfare. Rather, meat reduction relates to understandings of nutrition and vitality of the body, concerns about the conditions of meat provision, and the personal relationships and routine activities through which meals are sourced, prepared and eaten. The study highlights the variety in understandings underpinning the motivations and strategies of consumer meat reduction. The analysis contributes to the literature on sustainable consumption and production, with a case study of the lived experience of sustainable dietary change.
\end{abstract}

Keywords: sustainable consumption and production; meat; behaviour change; food; de-animalisation; plant-based diet; flexitarian

\section{Introduction}

Changes in the consumption patterns of western societies are fundamental to meeting sustainable development goals and climate change targets [1]. The importance of this is reflected in the vibrancy of interdisciplinary research in the area of 'sustainable consumption and production' (SCP). A key contribution of work in this area to date has been the identification of domains which contribute the most significant resource burden to society and consequently offer greatest potential for reducing environmental impacts. Following a review of SCP research, Tukker et al. [2] found that despite considerable variety in approach, data and indicators used within the field, a broad agreement exists about the key locations of environmental burdens. More specifically this research suggests that the three domains of mobility, housing and food are responsible for $70-80 \%$ of the lifecycle environmental impacts of society. Within these domains particular forms of activity are identified as especially problematic, including car and air transport (in mobility); heating/cooling, appliance use, building and demolition (in housing); and in the domain of food, the burden associated with animal-based agriculture and the production and consumption of meat. The considerable environmental implications of meat production, which include the significant use of land [3], water and energy, and the production of emissions and waste [4] has established meat as a fundamental issue in the development of more sustainable systems of consumption and production [5]. 
This paper aims to contribute to the growing literature on meat and sustainable consumption, which is briefly discussed in the context of this specific contribution. Meat eating is a long-studied topic in cultural and anthropological scholarship. Consequently, the historical social and cultural importance of meat eating is well established (e.g., [6]). More recently, in the context of discussions about the environmental and ethical implications of meat consumption, increasing attention has been paid to assessing the determinants of the quantity of meat eaten by different groups of people. This work has highlighted the tendency for the amount of meat eaten to vary according to various socio-economic categories including age, gender, social class and educational attainment [7]. Attention has also been paid to the propensity for individuals to adopt diets which avoid meat altogether-under the banners of 'vegetarianism' or 'veganism', on the basis of psychological traits, personal values, motivations and lifestyles (e.g., [8-10]). Valuable contributions have also been made in understanding consumers awareness, attitudes and intentions in relation to meat avoidance and plant-based eating [11,12], as well as studying the effectiveness of various forms of intervention to stimulate changes in meat consumption in the name of sustainable consumption (e.g., [13]).

In the context of this debate on meat consumption, the paper aims to enrich the understanding of the challenges and strategies used by people who attempt to enact meat-reduced diets. While abstinence from meat is relatively well studied (see [10] for a review), 'meat reduction', in which individuals diminish rather than abandon meat eating, has received relatively less attention. Nevertheless, various studies have identified meat reduction or 'flexitarianism' as desirable, both in terms of improving the sustainability of the food system and in relation to consumer dietary choices [11,12]. A UK survey conducted in 2014 found that $20 \%$ of respondents reported reducing their meat intake in the past year and 35\% reported a willingness adopt a meat-reduced diet in the future [14]. The aim of this paper is therefore to further explore the important, but as yet under-studied empirical phenomenon of 'meat reduction', a concrete instantiation of consumer action on sustainable consumption, and how it is enacted within the context of everyday life. This is approached through a qualitative exploration of meat-reducers' lived experience of meat eating and meat reduction, using data generated through in-depth interview, interpreted through the lens of a practice-oriented perspective on (sustainable) consumption. In the context of the relative lack of attention to this topic from this perspective, the study is explorative, intending to present and interpret some initial observations, to address the question: why and how do people go about reducing the amount of meat in they eat, and how this is experienced? The paper is structured as follows: Section 2 outlines the approach of the study, including the rationale for understanding 'meat reduction' as an enactment within the broader practice of eating and food provision, and the implications of this for data analysis. The context and method of data collection are outlined. Section 3 describes and interprets the insights generated from the study, discussing the themes of motivations, strategies and experiences of meat reduction in everyday life drawing on the accounts of three respondents for illustration. Section 4 highlights the key implications of the study and suggests some limitations and opportunities for future research.

\section{Approach of the Study}

\subsection{Meat Reduction within the Practice of Eating}

Over the past decade, the study of environmentally consequential consumption has benefited from insights from the sociology of consumption. This research has contributed to a shift in focus from individual consumers' environmentally significant behaviours as the core problem for sustainable consumption research, to include greater attention to the cultural, economic and material structuring of consumption (e.g., [15-17]). Important within this shift has been the uptake and development of the 'practice turn' [17], and the idea that people consume objects, resources and services not for their own sake, but in the course of accomplishing social practices [18]. Attention to practices as a perspective for understanding sustainable consumption has proved particularly fruitful in relation to 
the inconspicuous, resource-intensive activities which constitute everyday life-including those that map on to the key areas of environmental impact identified in the introduction. As such, a growing number of authors have argued that perspectives which place practices and their social organisation at the centre of analysis have a great deal to offer to understanding the conditions underpinning a shift to less resource-intensive ways of life $[17,19,20]$.

How to delineate practices in general, and the practice of eating in particular, has been the focus of considerable discussion [21]. Reckwitz's frequently cited definition provides a useful starting point, describing a practice as:

... a routinized type of behaviour which consists of several elements, interconnected to one another: forms of bodily activities, forms of mental activities, 'things' and their use, a background knowledge in the form of understanding, know-how, states of emotion and motivational knowledge. ([22]: p. 249)

In working through the question 'Is eating a practice?' Warde [21] sets out the concept of eating as a 'compound practice', suggesting that eating presupposes the intersection of at least four integrative practices which include the supplying of food, cooking, the organization of meal occasions, and aesthetic judgments of taste. The analysis of meat consumption presented in this paper builds on the idea that eating and its social organisation should be understood as constituted by four separate but 'integrated' sets of activities each with their own organisational underpinnings. This insight is operationalized by applying the method developed in Mylan and Southerton [23] to explore the coordination of practice. The method uses data generated by individuals' accounts of activity sequences performed in the context of everyday life to explore the range of social, cultural and institutional factors contributing to maintaining stability (or enabling change) in how things are done. In contrast to Mylan and Southerton [23], who aimed to understand the coordination of a particular practice (household laundry), the current study aims to examine how an established personal orientation (toward meat reduction) plays out in relation to the wider practice (of eating), to better understand how established routines, expectations, and circumstances within which eating takes place shape how meat reduction is enacted. Specifically, the research addresses the question why and how do people attempt to reduce their meat eating, and how is this experienced in the context of everyday eating and food provision? By exploring the lived experience of consuming less meat alongside the flow of everyday life, the research aims to shed light on the different ways these attempts are enabled or constrained by the way eating is currently organised.

\subsection{Data Collection}

The data used in this analysis was collected as part of a wider project on changes in food consumption in three English cities. The study included a representative survey of eating habits of the residents of three cities, conducted in 2015. Full details of the survey methodology have been published elsewhere [24]. The survey respondents were asked if they agreed to participate in future research, and those who agreed formed the population, which was used to recruit interview participants for four qualitative work packages, including the one reported herein. Respondents were allocated to the project on meat reduction on the basis of their response to questions about meat eating and attempting to reduce meat eating, ensuring that no participant was allocated to more than one work package. All respondents allocated to the project were residents of London, the city with the highest proportion of meat-reducers, in order to reduce the effect of potential geographical difference. Respondents who identified as vegetarians or vegans were omitted and an equal number of self-identified meat-reducers and non-meat-reducers were included. A sample of 51 people were allocated to the project, 26 of whom self-identified as trying to reduce the amount of meat they ate (from here on referred to as 'meat-reducers').

The 51 individuals were contacted by post in December 2015, outlining the aims and context for the study. The postal contact elicited two responses from individuals interested in taking part in the research. One of these individuals was subsequently interviewed. The remainder of the interviewees 
were recruited via telephone, progressing through the list until 20 interviews, including 10 with 'meat reducers' had been conducted. An equal number of reducers and non-reducers were interviewed, to enable a comparison between the accounts of reducers and non-reducers, and identification of the habits and narratives illustrative of the experiences of meat reduction. Interviews were conducted in two separate weeks in January and March 2016 in London, UK. Interviews took place either in the participant's home, or a public place (including five interviews in cafes, one in a museum and one in a park). One interview was conducted at the respondent's workplace. Interviews lasted between $1 \mathrm{hr} 15$ and $2 \mathrm{hr} 10$, were recorded and professionally transcribed in full.

The interview data was generated using a semi-structured interview protocol. Because the aim was to understand how meat reduction took place within the wider practice of eating, interviewees were initially asked to describe sequences of food-related activities from the previous day, including what they ate, why, where, when and with whom. These initial descriptions were further probed (with follow up questions) in relation to meat eating, purchase and preparation and meat avoidance. Three key activities were covered: (1) purchase and supply of food; (2) cookery and meal preparation; and (3) the social context of eating occasions (where, with whom and why eating took place).

The data generated from this method consists of rich, detailed descriptions of individuals' day-to-day eating habits, alongside reflection on decisions, motivations, challenges and emotions relating to moments of meat-consumption and non meat-consumption. In order to take advantage of the richness of the data on sustainable consumption in everyday life, insights from the study are presented with reference to three individual cases of meat-reducers' experiences, to illustrate and contextualise the findings from the interviews. The three individual cases were selected because: (1) the respondents gave articulate and detailed accounts (lasting over $1.5 \mathrm{~h}$ ); (2) the three cases of individual meat reducers exhibit variety in relation to age, gender, family circumstances and employment; and (3) the accounts differed in relation to their motivations and experiences of meat reduction in ways which reflect the specificities of the accounts of all the meat-reducers' interviewed, in comparison to non-meat reducers accounts. Names have been changed to preserve anonymity.

\section{Insights from the Study: Reducing Meat Consumption in Everyday Life}

\subsection{Motivations for Meat Reduction}

Respondents drew on a range of explanations when recounting why they had decided to reduce the amount of meat they eat. Personal motivations were recounted primarily in relation to health and individuals' bodies. These were explained in the context of both isolated events (such as diagnosis of illness) as well as general feelings of desire to improve overall health and 'get fit'. Such personal motivations for meat reduction were often positioned in the context of wider narratives, which extended beyond eating to other aspects of personal life, and a feeling that 'something needs to change'. Several interviewees recounted 'health scares' for themselves or family members as important motivations for meat reduction. While such 'scares' varied in nature (including a diagnoses of high cholesterol; risk of future illness due to body weight and a father's heart attack), common between them was their manifestation through encounters with medical professionals. Consequently the 'scares' appeared in contrast with the 'general feelings' which were described as developing more gradually, over longer periods, and explained with reference to ideas and information from wider range of sources, such as friends, family and the media. Nevertheless, even in cases when particular events were presented as the primary drivers for decisions to attempt to reduce meat eating, further exploration usually uncovered a range of contributing factors-including pre-existing thoughts and established associations between high meat intake and adverse effects on various aspects of health. Notably this was not the case for one interviewee who had, during the period between survey and interview, become vegetarian-omitting all meat from her diet. This newly vegetarian interviewee described enthusiastic meat consumption before a parent's heath scare, followed by an experience of 'enlightenment' during which dietary change was reportedly accompanied by changes in food 
provisioning routines, preparation skills, and the range of dishes that she cooked for herself and her partner.

While all meat-reducers drew on ideas of health in their explanations-these ideas did not share a common form between respondents. Alice, a self-employed professional in her 50s with two teenage children living at home, related her personal motivations for meat reduction to changes in her digestion, lifestyle and ultimately her age:

now that I've got older-yeah, I ate more meat when I was younger. So I was much more active, so you know, muscle-building or whatever, but now I just can't take that kind of quantity of [meat] in my digestion, basically Alice

Alice went on to explain her broader mind-set in relation to meat eating and diet, and in doing so illustrated how her view on 'balance' in her diet had consequences for meat provision in her home, and meat eating for other members of her family:

Nowadays it seems to be recommended much more of a vegetable-vegan diet. Which I actually don't necessarily agree with. I don't actually think just eating-cutting out certain things is a good idea. It's just always eat things in moderation. So yeah, you should have a balance through your diet. I know some people like to eat meat every day, but it's not something we would do, probably. (... ) I actually think it's healthy for people to eat some red meats in terms of the iron content, you know, sort of healthy for their bodies, isn't it? Alice

Alice's impression was of a growing societal pressure to reduce meat eating and noted increasingly frequent encounters with attempts to promote vegetarian and vegan eating. Alice did not agree with this latter approach to diet, citing nutritional reasons her explanation (related to iron intake), although she appeared unsure about this link and clearly enjoyed cooking and eating meat on a frequent basis. It was health and nutritional information that formed the basis of the initial explanation and rationalisation of Alice's approach to meat-in contrast to her explanation of motivations which related primarily to her own feelings of vitality within her body.

The centrality of health and the body in Alice's account of motivations for meat reduction was reflected across most interviewees-albeit in different ways. This variety is illustrated by comparison between Alice and Jamal, who is in his early 20s and lives with his mother while he studies engineering at university. Jamal expressed his primary motivations in relation to the resultant benefits for athletic fitness and bodily aesthetic. Jamal has been consciously trying to reduce the amount of meat he ate for the past two years. His account of why he decided to do so touched on multiple explanations. At the forefront of his mind was nutrition and its relation to fitness:

I think what happened was that I started going to the gym. (...) I believed that going to the gym would get me what I needed. But then I realised it's not just about that, it's about what you eat as well. That helps you with your gym development as well. So I started researching about it, my eating habits as well. I changed it quite a bit, what I eat now compared to 5 years ago. Jamal

Jamal's meat reduction has taken place alongside wider dietary change-reducing highly processed and sugar-heavy foods-which he referred to as 'junk'. For Jamal eating and food selection is about fueling his body. Meat was referenced according to its bio-chemical characteristics as protein, fats, cholesterol and energy. Within Jamal's process of dietary improvement, the status of meat appeared ambiguous. Considered in terms of protein, meat was a valuable foodstuff and not to be omitted. But when referred to as fat, understood variously as 'bad fats', 'cholesterol' and 'transfats', reasons to cut down meat intake emerged. Micronutrients such as iron, which were important to Alice's meat reduction motivations, did not feature. However, Alice and Jamal did share a perception of the link between meat and muscle development. This was treated as malleable by Jamal, who saw adjustments in meat eating (quantity, quality and timing) as a tool for improving the appearance of his body, while for Alice muscle development (or lack of it) was an inevitable by-product of the changes in her lifestyle and metabolism during her life course, which she responded to by altering her meat intake. 
All interviewees gave accounts in which personal motivations for meat reduction were explained with reference to their bodies relating to function (such as digestion or strength), aesthetics (such as muscles or bodyweight), and health (including freedom from illness and cardiovascular fitness). In addition, personal motivations in relation to the body were also recounted by some interviewees in relation to changes in personal circumstances, which were presented as 'triggers' for reflection on diet and subsequent action on meat reduction. These included changes in family relationships and employment status, such as children moving out of home (two interviewees), divorce (one interviewee), bereavement (one interviewee) retirement (one interviewee) and a new job (one interviewee). It was in the context of changing personal circumstances that the constraining influence of other people's expectations came to the fore. These were often experienced as a liberation, in which changing routines offered opportunities for freedom from previously established ways of providing and eating food. Half the meat-reducers interviewed recounted taking advantage of being alone more frequently to eat in a different way-with the inclusion of less meat in the diet.

Most accounts of personal motivations were further situated with reference to the conditions of meat production and provision as they developed during the interview. This included recounting concerns about agricultural production, most notably the use of hormones and antibiotics in animal rearing; the practices of slaughtering and butchering (and the hygiene and ethics of this) and the quality of meat products available to purchase from supermarkets and restaurants. Many respondents expressed concerns about the quality of meat associated with particular products (e.g., burgers; ready meals) and certain types of restaurant (e.g., fast food restaurants; kebab shops). Central to these accounts was the issue of trust, and what or who could be trusted in relation to meat. Knowledge about potentially concerning issues of ethics, hygiene, safety, health and environmental sustainability of meat production and consumption were variable in both quality and quantity. As such, the conclusions drawn by meat-reducers in relation to questions of trust were not shared, in several cases exhibiting opposed conclusions, for example, in relation to the role of supermarkets in providing high quality meat, and meat quality on offer in fast-food restaurants. The variety in the trust engendered by different ways of accessing meat observed across the interviewees is likely to be a reflection of the multiple institutional underpinnings of trust in food across different populations, which is acutely apparent in relation to meat [25].

All the meat-reducers interviewed (as well as most non-reducers) recounted some general concern about meat quality and how it was provisioned, some experiencing this as anxiety. However, respondents were not acutely aware of specific consumer campaigns to raise awareness of these issues, less than half the meat-reducers were able to accurately name a meat consumption related campaign when asked. Terry, who is in his 60s, has two grown up children, lives with his wife and works part time as a school teacher, responded in a way which reflected this. When asked if he was aware of any attempts to influence meat consumption, his answer was quite typical in suggesting a 'general impression' rather than knowledge of particular initiative:

... the general impression is that they're trying to get people to eat less meat because it's healthier for you in terms of vegetables, more vegetables and fruit. Just a better balance, rather than a high-protein diet.

Terry generally tried to reduce meat eating, but expressed less concern about 'healthy eating' than either Alice or Jamal, and relied more heavily on an experiential explanations emphasising that he prefers to eat fish. Nevertheless, he did hold established views which situated less meat eating as part of a 'healthy lifestyle', but did not relate this to changing his body as both Alice and Jamal had done. Rather, Terry emphasised balance (in terms of varied diet) and moderation (in red meat and 'fatty' and 'processed' foods in general).

While individuals gave different explanations of their motivations for reducing meat eating, common to all accounts was the mobilisation of personal reasons (in relation to various aspects of health), which were usually situated alongside perceptions (often expressed as anxieties) in relation to the wider food system. Having considered peoples' stated motivations for reducing meat eating, 
the next section turns the ways in which they attempt to act upon these motivations by enacting meat reduction.

\subsection{Strategies for Meat Reduction}

Three strategies appeared most prominently in interviewees' accounts of their efforts to reduce meat eating. The first was avoiding meals in which a main dish included meat as a central ingredient; the second was replacing meat in traditionally meat-based dishes with alternative ingredients; and the third was altering the repertoire of meals or dishes that were regularly prepared, in order to decrease the occurrence of meat-based meals over a given time period. These strategies are not mutually exclusive, for example creating new meat-reduced dishes (strategy 2) often played a role in changing the weekly menu (strategy 3). Nevertheless, for the purposes of analysis, their separation enables a closer examination of the different ways in which purposive action toward meat reduction is negotiated alongside the existing activities of eating and food provision.

Eating non-meat meals was a strategy reported by all interviewees in the enactment of meat reduction. Not surprisingly eating non-meat meals was also reported by respondents who did not self-identity as meat reducers. The qualitative nature of this research means that a quantification of how often non-meat meals were eaten by meat reducers is not possible, but data from the interviews suggest that this was meat-reducers' most frequently deployed strategy, and likely to be the most significant in terms of volume of meat reduction.

Where, how and by whom the food was prepared and served all played a key role in the avoidance of meaty meals. Meat-based meal avoidance was often enacted in circumstances of self-provisioning and solo eating. In these circumstances it was described as a positive, satisfying choice. In other circumstances, notably eating out with other people, for example when Jamal was obliged to accompany friends to a kebab shop on his lunch break from University, the selection of the non-meat meal was undertaken grudgingly. More generally for Jamal, the type of eating outlet had a strong effect on whether and what type of meat he would eat. Familiarity with the particular restaurant, or the menu, influenced the selections that were made. Past experiences of both eating commercially provisioned meals, and eating socially at other peoples' homes shaped the likelihood that meat reduction would be enacted:

if I don't know that restaurant, then I'll say "ok I won't have the meat option because I'm not too sure about it." But a place like Nandos or Gourmet Burger Kitchen, they have a menu I can trust, I've been there before. But if it's a new place I haven't been before I'm very careful about that kind of thing. But I do try to cut down the meat that I have now, at home as well. Jamal

Alice also recounted avoiding meat-dishes when eating out of home. In her account this was more specifically linked to certainty about provenance, aligning with her explanations of motivations for meat reduction described above.

sometimes, if you ask at a restaurant, they will tell you [where meat comes from]. They will say 'Yeah, it's from the local farm. Or they state their products are organic. Sourced from within a 10-mile radius, and things like that. But you know, you can't do that $100 \%$. It's not up to you if the restaurant does its end. I'm not a picky eater as such, you know, but if it's more obvious where things are from-if it isn't, I'd probably go for things like pasta. Alice

Both Jamal and Alice's avoidance of meaty dishes when eating out of home were shaped by the degree of trust for the establishment and the food provided-but these were negotiated in quite different ways. While Jamal relied on his own past experience and familiarity to make a judgment, Alice sought particular types of information provided by the restaurant. Ultimately different types of knowledge were being mobilised to shape the circumstances which meat avoidance was enacted. This serves as an illustration of the importance of looking beyond aggregated consumer purchase decisions in the search to understand the underlying mechanisms through which a reduction in meat 
consumption might be achieved as decisions which might appear similar in terms of the non-meat meals purchased are influenced by different types of knowledge and motivations.

The replacement of meat with non-meat ingredients was the favoured approach of some meat-reducers, while not deployed by others. This strategy, which aimed to keep dishes and meals relatively unchanged from existing meaty versions, was deployed by some interviewees because it engendered feelings of familiarity which were deemed particularly important when cooking for others. Replacing meat in established dishes was done in a variety of ways. For Terry this included swapping meat for fish:

I found a recipe where you do a spaghetti bolognaise, but you do it with anchovies, which is very very tasty.

INTERVIEWER: Instead of the meat?

PARTICIPANT: Yeah. You know, parsley, garlic, tins of tomatoes, grated cheese. So it looks like normal but you use tins of anchovies instead of meat, and that's one of my standards [meals], everybody expects to see that. And quite often they say, "we really enjoyed that, dad" so it's one of my staples. I have a fairly short list of things that I invariably do. I've been doing that recipe for too many years to stop.

None of the interviewees mentioned the inclusion of foods marketed as 'meat alternatives' in the context of adapting existing dishes to replace meat, although most had tried using them at some time. When meat ingredient replacement was deployed it included fish, as described above by Terry, vegetables, or most frequently pulses or beans. This strategy also involved altering dishes to reduce the volume of meat included as an ingredient (such as in stews or curries). The idea of reducing the size of a portion of meat that was served on its own (for example a steak), and compensating with an accompaniment, was not described as a strategy for meat reduction. Indeed, Alice specifically noted the importance of maintaining the size of lone meat-pieces, noting that this was enabled by reducing or eliminating meat in other meals. For Alice the joy of eating meat would be tempered in the context of smaller portions in meals where meat was the 'main event' such as in a roast dinner. She explained that she would feel ungenerous if she was providing the meal and unsatisfied if she was eating it. Replacing meat with other ingredients is a strategy which depends on the style of meal being served, and to some extent the nature of the meal occasion-as discussed more fully in the following section.

Planning meals and rotating dishes is perhaps the most intriguing strategy for enacting meat reduction identified in this study. While the timeframe varied, for those who explained their meat reduction in this way, it was associated with the main meal of the day and entailed a 'rota' of dishes, as described by Alice:

I try and balance out a week with different things, so it would be, you know, a chicken, or beef or lamb, then pasta, then maybe a salad, a jacket potato, something like that, now maybe more the others than the meat. Just do a sort of five or six or ten day kind of rota of different types of meats and other stuff. Alice

The use of a relatively stable repertoire of dishes which are eaten and provided within a household has been previously interpreted as a way of practically negotiating multiple pressures of everyday life, through reliance on habit [19]. In these interpretations, such routines effectively reduce the cognitive load of the person providing the food, limiting the requirement to rethink and reorganise (including deciding on appropriate dishes, sourcing ingredients, preparing, cooking, and the managing risks of dissatisfaction associated with new encounters). A change to the established repertoire, in favour of less meat-based meals, is thus more likely to be a stable, longer term change-and therefore has important implications for sustainable consumption.

Terry also recounted the rotation of meat-based with non-meat based dishes, but on a slightly shorter timeframe than Alice: 
So if we've had prawns, I do love prawns, even if they're rubbish prawns, I still like them. (... ) So maybe the ying and yang, if I had that last night then I might buy meat. I'm not sure it's the case, but it might be ying and yang going on. And whether it's to do with health or flavour or what I fancy, there's a whole manure of things going on in my head. But it's quite a limited palette, thinking about it. Terry

Similar to Alice, Terry's rotation of dishes included an awareness of creating 'balance' (in this case described as 'ying and yang') in the occurrence of meat on the menu over time, but involved less forward planning than in Alice's case. Terry acknowledges he cannot fully explain why particular meals follow others, in the quote above citing health, flavour or 'just what he fancies'. This is in contrast to the experience of constraints on non-meat eating which are primarily recounted as involving other people (as discussed below). Nevertheless, both Alice and Terry reflected the accounts of several of the meat-reducers interviewed who described rotating and planning meals as a way of managing meat consumption. These plans attempted to space out non-meat meals. Although the timespans varied, the implication is that too much time between meat consumption, particularly for other people, is not considered desirable. This points to the potential for 'stretching out' the time between meat eating as a way of promoting meat reduction, in contrast to current NGO-led campaigns which suggest omitting meat to a particular schedule (e.g., one day per week).

\subsection{Living Meat Reduction}

Respondents' lived experiences of meat reduction varied markedly and included feelings of satisfaction, liberation, achievement, boredom, drudgery and frustration. Jamal experienced meat reduction as a challenge. Central to this explanation was the availability of acceptable options to eat with others-a theme that appeared in the majority of meat-reducers accounts. This came to the fore for Jamal when eating outside of the home:

"It [reducing meat eating] was hard, I'll be honest, it was hard. Because like most of the places around me-especially at Uni and stuff-when we'd go out to eat, it's mostly just meat, just meat places. So my friends would say "let's go out to eat" and the only places that would allow us to get back in time as well—mostly are meat places like kebab shops and chicken places as well." Jamal

At home Jamal's intentions to reduce meat were more easily translated into desired outcomes. Even when meat-based meals were provided by Jamal's mother, the potential for adaptation and improvisation, and the perceived lack of social sanctions for doing so, meant that his preferences for less meat could be accommodated, which was experienced as less frustrating and more satisfactory. Data is not available on how Jamal's mother experienced this process. However, the accounts of other interviewees indicated that the preferences of family members play a key role in shaping the experience of meat reduction for the reducer, and meat-reducers also noted the importance of close family members in providing initial motivations to change diet. Terry for example, recounted multiple ways in which his family constrained his meat reduction, which ultimately meant he found it easier to avoid meat when eating outside the home (in contrast to Jamal). The constraints imposed by Terry's family related to his understanding of their joy and expectation of the provision of meat, for example in the family meal on Sunday:

My kids love a roast, so it'll be pork or chicken, roast potato, vegetables. That's what the kids love. So Sunday's that. Terry

It is possible that Terry's children would also enjoy something else, but the family routine is such that the provision of a Sunday meat roast is expected, implicitly agreed upon, and repeated without challenge. In addition to his children, Terry's wife is also influential in how Terry experiences meat reduction. This was felt less in terms of specific meals and more in relation to wider ideas of proper eating: 
I am a carnivore and I probably always will be a carnivore (... ) If I had a partner that really said, we're not going to eat any more meat, I'd go along with it. But my wife... I mean she's not... she likes a varied diet. And so do I. Terry

Terry's wife's understanding of a 'varied diet', which Terry ultimately agrees with, necessitates the inclusion of meat. The desirability of variety, which also appeared in Alice's descriptions of feeding her family (above), was found in most of the meat-reducers accounts. Notably it was mobilised in support of both meat reduction (reducing meat creating opportunity for greater variety of other food types) as well as against meat exclusion (a varied diet entails all types of food, including meat). In Terry's case, his wife's concern with variety plays out in the context of Terry's relatively limited repertoire of the dishes he cooks (see above). As such, Terry's enactment of meat reduction takes shape through a process of negotiation between his understandings of a healthy diet, the anticipated desires of other people, and his trusted, familiar dishes.

Terry's account illustrates the importance of immediate family circumstances in opportunities for enacting meat reduction, which was a theme running through each of the interviews. Despite the constraints placed upon him by other people, in contrast to Jamal, Terry recounted enjoying meat reduction - which he experienced as opening up opportunities for other more delightful eating experiences. Meat-free dishes were described with joy, and in some instances sentimentality:

I had a girlfriend back in the day, thirty years ago, and she was very much into pulses and she was forever cooking lovely things. She did the black-eye bean bake, I used to try and make that as well, which was almost like meat, very tasty. I sometimes do that. Terry

Similarly for Alice, meat reduction was viewed as something which maximised the joy of eating. This is experienced differently from Terry however, by ensuring that the meat she does consume has certain preferential characteristics (in contrast to Terry who emphasises enjoyment of non-meat dishes). Alice aims to avoid 'bad quality' meat rather than meat in general. Alice is effectively re-categorising meat to enable continued consumption, while simultaneously responding to the concerns which prompt her to adjust her diet. In order to do so Alice draws on knowledge about how and where meat is produced (in contrast to Terry whose narrative relies on his wife's idea of a healthy diet). By categorising some types of meat as 'bad meat', the contrasting 'good meat' can be eaten regularly and with enjoyment, which Alice does on average five times a week as part of her main meal.

Entertaining guests at home, and to a lesser extent feeding family, was a key challenge for meat-reducers. Alice viewed both occasions as inappropriate for avoiding or limiting meat. When describing feeding extended family at home, she explained:

I tend to do a big sort of casserole, so we'll do chicken breasts with chorizo sausages and tomatoes and onions and put it all in, and then I'd do rice or pasta and put it on the table, and everyone can help themselves.

INTERVIEWER: Why would you choose that?

PARTICIPANT: It's just an easy dish to do, and one of them [only] eats chicken, so if she's coming I'll do chicken, obviously. If I do something else, sometimes I will cater and do a separate chicken, because I know it will get used in sandwiches, and it lasts a long time. But yeah, I don't want to force her to eat red meat if she doesn't like it. Alice

Alice's account of providing a meal for family touches on several themes which were common to meat-reducers' explanations of when less meat was desirable or appropriate. The first is the ease with which the meal could be provided. The inclusion of meat was generally considered to be a less effort-intensive way of providing an acceptable meal. The second is the idea that proper meals contain meat. Alice's niece does not eat any other type of meat apart from chicken. As such chicken must be provided, to the extent that other meaty dishes might be accompanied by additional chicken because the availability of no meat for Alice's niece would be so unusual that it is not even considered a possibility. The third theme is that meat saves time. Not only in planning a menu and cooking a meal, 
but also in the use of meaty leftovers which can be re-purposed to provide sustenance at a later time. Planning ahead, and the occurrence future activities, such as described by Alice in relation to chicken sandwiches (in the context of her son's football practice), exert influence in sustaining meat as an important part of diet. Ease, flexibility, and convenience were all positive meanings embodied by meat. Significantly, the conditions in which these characteristics (that meat is easy and convenient) take shape extend beyond the particular dishes of which they form a part, supporting the observation that meat is not required as part of a 'spaghetti bolognaise' (which as Terry's description above illustrates-it is not). Rather, the fact that meat is taken for granted as an easy and convenient way of providing appropriate food is reproduced alongside multiple activities of daily life-including managing weekly schedules (as for Alice who cooks roast chicken in anticipation of sandwiches after football), and organising meal occasions (as Terry does for Sunday dinner with his children). This observation emphasises the importance of looking beyond the selection of dishes at moments of eating in order to identify the factors that hold meat eating and meat provision stable alongside multiple activities of daily life, even in the face of concerted attempts to reduce it.

\section{Discussion and Conclusions}

Existing research indicates that an increasing number of people report a desire to reduce their consumption of meat and other animal-derived products. This is reflected in the responses of commercial food processors, supermarkets and restaurants where the marketing of meat-free options is on the rise. At the same time, consumers' awareness of the links between meat eating and environmental problems remains low in the UK and beyond [26]. Aligning with the findings of previous research on the motivations for consumer meat reduction [11,12], this study found only limited significance for 'environmental' concerns as motivators for meat reduction, with 'health' the most prominent influence. The contribution of the current study to that existing insight is the demonstration of the considerable diversity in the interpretation of the 'health' implications of meat eating, as well as the implications of this for the experience of meat reduction in everyday life. Notably, this diversity was apparent not only between interviewees, but also within individuals' own accounts-varying across the different constituent activities of eating-including sourcing food; cooking; eating out; providing for others; and planning for the week ahead. As such, individuals' meat reduction was explained by drawing from different understandings of health and nutrition across different types of meal occasions (such as entertaining friends, or providing sustenance after the gym), compared to descriptions of how food was purchased and which options were selected. The different health motivations drew from separate sources of knowledge in order to explain and rationalise motivations for meat reduction. While meat-reducers did exhibit uneasiness in relation to the conditions of meat production and provision, there was little sense of lack of trust in lay, media or expert knowledge related to meat consumption and its impact on health specifically. While this observation could be an artefact of the study design (in which individuals explained motivations to reduce meat and are therefore more likely to trust the information they mobilise in these explanations) it appeared in contrast to the broader narratives of food provision alongside which personal reasons for meat reduction were situated.

This paper has explored the motivations, strategies and experiences of enacting 'sustainable consumption' in everyday life, using the case of reduced meat eating. Changes in meat consumption are increasingly suggested as pivotal to a more sustainable food system-particularly in light of the massive climate change impact of animal agriculture. While considerable research exists relating to the motivations for complete omission of meat from the diet, this paper contributes to the emerging body of work concerned with undertaking 'meat reduction', or 'flexitarianism', by exploring how people who eat meat, but want to eat less, negotiate this endeavour in the context of everyday life. The study highlights the variety in motivations, challenges and lived experiences of meat reduction, which can be observed not only between individuals, or as similarities according to relevant socio-demographic variables (e.g., age or gender), but across the various activities that constitute the wider practice of eating. The study contributes an additional empirical case to the growing body of work suggesting 
that the role of consumer-citizens in generating change is best viewed from a perspective which takes account of wider social, cultural and institutional constraints that shape conduct in everyday life. In the case of consumers taking action on sustainable consumption of meat, the study demonstrates that this was frequently constrained by the prospect of social sanctions, in the form of the disappointment of others, unsatisfying participation in social occasions, or anticipation of wasted time and effort, which effectively curbed the enactment of meat reduction. The wider suggestion is that people are unlikely to straightforwardly negotiate novel acts of sustainable consumption, or establish more sustainable routines to the extent they consider possible or necessary, even when they are appropriately motivated to do so.

An important limitation of this study is that the methods used do not enable any quantitative assessment of the effectiveness of the meat reduction strategies observed, or the relative implications of the factors that constrain them. As such, a useful avenue for future research would be to further explore changes in the dietary composition of meat-reducers over time and across various daily life contexts, using methods such self-completed food diaries. Designing such a study based on the findings of this research would generate valuable data about the contributions of consumers' efforts to reduce meat consumption and their role in the enactment of sustainable consumption in everyday life.

Acknowledgments: This research presented in this article was supported by the University of Manchester Sustainable Consumption Institute project 'Innovation for Sustainable Meat'.

Conflicts of Interest: The authors declare no conflict of interest.

\section{References}

1. Girod, B.; van Vuuren, D.P.; Hertwich, E.G. Climate policy through changing consumption choices: Options and obstacles for reducing greenhouse gas emissions. Glob. Environ. Chang. 2014, 25, 5-15. [CrossRef]

2. Tukker, A.; Emmert, S.; Charter, M.; Vezzoli, C.; Sto, E.; Andersen, M.M.; Geerken, T.; Tischner, U.; Lahlou, S. Fostering change to sustainable consumption and production: An evidence based view. J. Clean. Prod. 2008, 16, 1218-1225. [CrossRef]

3. Tilman, D.; Fargione, J.; Wolff, B.; D'antonio, C.; Dobson, A.; Howarth, R.; Schindler, D.; Schlesinger, W.H.; Simberloff, D.; Swackhamer, D. Forecasting agriculturally driven global environmental change. Science 2001, 292, 281-284. [CrossRef] [PubMed]

4. Pimentel, D.; Pimentel, M. Sustainability of meat-based and plant-based diets and the environment. Am. J. Clin. Nutr. 2003, 78, 660S-663S. [CrossRef] [PubMed]

5. D'Silva, J.; Webster, J. (Eds.) The Meat Crisis: Developing More Sustainable and Ethical Production and Consumption; Routledge, Earthscan: London, UK, 2010.

6. Fiddes, N. Meat: A Natural Symbol; Routledge: London, UK, 1991.

7. Gossard, M.H.; York, R. Social structural influences on meat consumption. Hum. Ecol. Rev. 2003, 10, 1-9.

8. Campbell-Arvai, V.; Arvai, J.; Kalof, L. Motivating sustainable food choices: The role of nudges, value orientation, and information provision. Environ. Behav. 2014, 46, 453-475. [CrossRef]

9. De Boer, J.; Hoogland, C.T.; Boersema, J.J. Towards more sustainable food choices: Value priorities and motivational orientations. Food Qual. Preference 2007, 18, 985-996. [CrossRef]

10. Ruby, M.B. Vegetarianism. A blossoming field of study. Appetite 2012, 58, 141-150. [CrossRef] [PubMed]

11. De Bakker, E.; Degavos, H. Reducing Meat Consumption in Today's Consumer Society: Questioning the Citizen-Consumer Gap. J. Agric. Environ. Ethics 2012, 25, 877-894. [CrossRef]

12. Latvala, T.; Niva, M.; Mäkelä, J.; Pouta, E.; Heikkilä, J.; Kotro, J.; Forsman-Hugg, S. Diversifying meat consumption patterns: Consumers' self-reported past behaviour and intentions for change. Meat Sci. 2012, 92, 71-77. [CrossRef] [PubMed]

13. De Groeve, B.; Bleys, B. Less meat initiatives at Ghent University: Assessing the support among students and how to increase it. Sustainability 2017, 9, 1550. [CrossRef]

14. Dibb, S.; Fitzpatrick, I. Let's Talk about Meat: Changing Dietary Behaviour for the 21st Century. Eating Better. 2014. Available online: https:/ / www.eating-better.org/uploads/Documents/LetsTalkAboutMeat. pdf (accessed on 1 June 2018).

15. Cohen, M.; Murphy, J. Exploring Sustainable Consumption; Pergamon Press: Amsterdam, The Netherlands, 2001. 
16. Gronow, J.; Warde, A. (Eds.) Ordinary Consumption; Psychology Press: London, UK; New York, NY, USA, 2001.

17. Shove, E.; Spurling, N. Sustainable Practices: Social Theory and Climate Change; Routledge: London, UK, 2013.

18. Schatzki, T.R.; Knorr-Cetina, K.; von Savigny, E. The Practice Turn in Contemporary Theory; Routledge: London, UK, 2001.

19. Warde, A. Consumption and Theories of Practice. J. Consum. Cult. 2005, 5, 131-153. [CrossRef]

20. Southerton, D.; Chappells, H.; Van Vliet, B. Sustainable Consumption: The Implications of Changing Infrastructures of Provision; Edward Elgar: Cheltenham, UK, 2004.

21. Warde, A. The Practice of Eating; Polity: Cambridge, UK; 2016.

22. Reckwitz, A. Toward a theory of social practices: A development in culturalist theorizing. Eur. J. Soc. Theory 2002, 5, 243-263. [CrossRef]

23. Mylan, J.; Southerton, D. The social ordering of an everyday practice: The case of laundry. Sociology 2017. [CrossRef]

24. Paddock, J.; Warde, A.; Whillans, J. The changing meaning of eating out in three English cities 1995-2015. Appetite 2017, 119, 5-13. [CrossRef] [PubMed]

25. Kjaernes, U.; Harvey, M.; Warde, A. Trust in Food: A Comparative and Institutional Analysis; Pelgrave Macmillan: Basingstoke, UK, 2007.

26. Wellesley, L.; Happer, C.; Froggert, A. Changing Climate Changing Diet: Pathways to Lower Meat Consumption; The Royal Institute of International Affairs, Chatham House: London, UK, 2015.

(C) 2018 by the author. Licensee MDPI, Basel, Switzerland. This article is an open access article distributed under the terms and conditions of the Creative Commons Attribution (CC BY) license (http:/ / creativecommons.org/licenses/by/4.0/). 